\title{
Knowledge, Attitudes and Practices of Patients Diagnosed with Tuberculosis Related to Tuberculosis Treatment Adherence in Keetmanshoop District, Namibia
}

\author{
Elizabeth Kateta $^{1, *}$, Josephine De Villiers ${ }^{2}$, Hermine Iita ${ }^{3}$ \\ ${ }^{1}$ Regional Health Training Centre, Keetmanshoop, Namibia \\ ${ }^{2}$ Nursing Degree Studies Nursing Science, University of Namibia, Windhoek Namibia \\ ${ }^{3}$ School of Public Health, University of Namibia, Oshakati Campus, Namibia
}

Received December 26, 2019; Revised February 2, 2020; Accepted February 6, 2020

Copyright $\mathrm{C} 2020$ by authors, all rights reserved. Authors agree that this article remains permanently open access under the terms of the Creative Commons Attribution License 4.0 International License

\begin{abstract}
Ensuring that patients in chronic care and treatment such as tuberculosis adhere to medications has implications for their quality of life, health care costs and society at large. The purpose of this study was to assess and describe the knowledge, attitudes and practices of patients diagnosed with tuberculosis (TB) related to their treatments in Keetmanshoop district in Karas region, Namibia. A quantitative, cross sectional study was done among 76 patients who were receiving their TB treatment at various treatment centres in the district. Probability systematic random sampling method was used to select the participant for the study. Data was collected using a structured questionnaire, which was administered by trained interviewers. Data was analyzed using Epi-info software version 7. Analysis was done by means of a univariate and bi-variate analysis and association were explored using chi-squared test. The respondents were 18 to 60 years old of which $57.89 \%$ were male and $42.11 \%$ were female. The findings of the study revealed that the respondents had a good knowledge on tuberculosis with regards to signs and symptoms of the disease. There was poor knowledge and misperceptions exist on the risk factors associated with transmission of tuberculosis such as shaking hands and drinking from the same cup with others. One third of the respondents $(33 \%, \mathrm{n}=25)$ had missed their treatment and the main reasons given for interrupting the medication were forgetting to take the pills, long distance to health facility and not enough food to eat before taking pills. Treatment adherence is a big challenge in management and control of tuberculosis. Therefore, community and patient education and material support to patients remain important to ensure adherence to tuberculosis treatment. Stakeholder contributions and
\end{abstract}

support are required to stem the scourge of TB in Namibia and globally.

Keywords Adherence, Attitudes, Knowledge, Patient, Practice, Tuberculosis

\section{Introduction}

\subsection{Introduction and Orientation to the Study}

Globally, tuberculosis (TB) is a serious public health problem and is one of the top killer diseases. In 2011, an estimated 8.7 million new cases of TB were reported worldwide and 1.4 million people died from TB (World Health Organization [WHO], 2012). The five countries with the largest number of TB case notifications in 2011 were India ( 2.0 million-2.5 million), China ( 0.9 million1.1 million), South Africa (0.4 million-0.6 million), Indonesia (0.4 million-0.5 million) and Pakistan (0.3 million-0.5 million) (WHO, 2012). India and China alone accounted for $26 \%$ and $12 \%$ of global cases, respectively (WHO, 2012).

A study done in sub-Saharan Africa on a review of compliance to anti-tuberculosis treatment and risk factors for defaulter treatment revealed a high rate of patients who did not turn up for their tuberculosis treatment follow up (Castelnuovo, 2010). In the study the proportion of patients defaulting varied from $11.3 \%$ to $29.6 \%$ between investigated countries. In four studies that were evaluated by Castelnuovo (2010) the majority of the patients' 
defaulted treatment during the continuation phase (patient on tuberculosis treatment received initials phase of two months' treatment regimen and will continue further four months' regimen to complete 6 months' treatment.) The identified risk factors for defaulting were: distance from the hospitals, lack of repeated smears, unit transfer after the intensive phase, (i.e, the initial two months of treatment), experiencing side effects of the treatment, having no family support, poor knowledge about TB treatment, being more than 25 years old, and depending on public transport (Castelnuovo, 2010).

Namibia has one of the highest case notification rates (CNR) of TB in the world with 11,145 cases of TB notified in 2011, equivalent to a CNR of 545/100,000 population (Ministry of Health and Social Services [MoHSS], 2012b). Namibia remained among the top five ranked countries in the world with the highest per capita tuberculosis disease (MoHSS, 2016).

A number of strategies have been adopted to deal with the increasing TB burden in Namibia and worldwide. Directly Observed Treatment (DOT) service is a component of Directly Observed Treatment Short-course (DOTS) strategy whereby TB patients take medicines under supervision and support from others, a nurse, relative or community member (MoHSS, 2012a). TB-DOT promotes adherence to and completeness of TB treatment under supervision. First-line anti-TB medicines (Rifampicin (R), Isoniazid (H), Pyrazinamide (Z), Streptomycin (S), and Ethambutol (E) are taken for a six months course and can cure Tuberculosis if medication is taken according to the prescription without interruption (MoHSS, 2012a). Despite TB-DOT being practiced in Namibia, a number of TB defaulters, failures, multi-drug resistance tuberculosis (MDR-TB) and deaths are reported (MoHSS, 2012b).

In Namibia, according to statistics from MoHSS National Tuberculosis and Leprosy Control Programme (NTLCP), //Karas, Hardap and Erongo regions are the regions with the highest TB burden in the country. The MoHSS -NTLCP Annual report (2012 - 2013) indicates the following TB treatment outcome for retreatment cases in 2012: nationally Namibia reported TB failure rate of $10 \%$, defaulter rate of $7 \%$ and death rate of $8 \%, / /$ Karas region reported TB failure rate of $7 \%$, and defaulter rate of $6 \%$; Hardap region a failure rate of $10 \%$, and defaulter rate of $4 \%$; while Erongo region reported failure rate of $4 \%$ and defaulter of $2 \%$. //Karas region is one of the areas most threatened by $\mathrm{TB}$, as it has the highest case notification rate in the country (CNR 996/1000) (MoHSS, 2012b).

Treatment success rate for re-treatment cases nationally for Namibia was reported as $73 \%$; / Karas region $78 \%$, Hardap 77\% and Erongo 86\% for the 2011 cohort; overall, the treatment success rate both nationally and for these high TB burden regions was below the $90 \%$ target (MoHSS, 2012a). Successful completion of treatment for patients who default depends on the patients' knowledge, attitude and practice towards the control of TB (MoHSS, 2012a). The total number of TB patients who were registered as defaulters and/or treatments interrupters in 2012 were 54 (MoHSS, 2012a).

Generally, there is a non-satisfactory level of knowledge among TB patients based on the studies done in Namibia and worldwide on factors associated with treatment non-adherence (Mainga, 2008; Mangesho et al., 2012). Due to the enormity of the TB situation and challenges faced in managing TB patient in //Karas region the researcher thought it worthwhile to assess the knowledge, attitudes and practices of patients diagnosed with TB with regards to their TB treatment in the region. The researcher did not come across any research done regarding patients' knowledge, attitudes and practices on tuberculosis treatment in Keetmanshoop district specifically. It is therefore important to determine the knowledge, attitudes and practices of patients regarding TB treatment adherence in Keetmanshoop district, in the //Karas region.

\subsection{Purpose of the Study}

The purpose of this study was to assess and describe the knowledge, attitudes and practices of patients with TB, related to tuberculosis treatment in Keetmanshoop district.

\subsection{The Objectives of This Study Were to}

- Assess the knowledge, attitudes and practices of the patients on tuberculosis treatment in Keetmanshoop district.

- Describe and assess how the knowledge, attitudes and practices of patients who are on tuberculosis treatment in Keetmanshoop district affect their adherence to tuberculosis treatment.

\section{Research Methodology}

A quantitative, cross sectional study was done among 76 patients who were receiving their TB treatment at various treatment centres in the Keetmamshoop district and systematically selected to participate in the study. Probabilistic sampling methods are designed to increase representativeness and decrease systematic bias in quantitative and outcome studies (Grove et al., 2015). Probabilistic systematic sampling also called interval sampling method was used to select every second patient who visited the health facilities for tuberculosis treatment during data collection period for participation in the study.

The researcher developed a questionnaire with closed-ended questions for the study.

The questionnaire comprised of 3 sections:

Section A - Demographic data of the participants;

Section B - Knowledge. - Patients' basic information with regards to TB as a disease and its treatment; and,

Section C - Questions about the patients' attitudes and 
practices

To measure validity, the questions for the research questionnaire were constructed from relevant literature reviews. The pilot test helped in ensuring to face validity and was done on ten patients who were on tuberculosis treatment at Keetmanshoop district to measure their knowledge, attitudes and practices related to treatment adherence. To ensure that the questionnaire was only administered by the trained TB field health promoters.

Data were collected between October and December 2016. The researcher engaged the services of six TB Field Health Promoters, as research assistants, who usually work in the health facilities and in the community on $\mathrm{TB}$ services.

The researcher and research assistants interviewed the respondents as they came to collect their daily or monthly TB treatments at Keetmanshoop district health facilities. Once a patient who met the criteria was identified, every second patient in that category was invited to participate in the study and once agreed, interviews were carried out in a room identified in the health facility for this purpose.

\subsection{Data Analysis}

Data were entered in a Microsoft Excel software programme and analysis done using Epi-info software version 7. Analysis consisted of initial univariate analysis, which looked at the frequencies and proportions of different variables. Bar graphs, pie charts and tables were used to present the data. A bi-variate analysis was used to determine the association between key variables such as gender, age, knowledge, attitudes and practices related to adherences. A chi-squared test was used to test for relationships between the dependent (level of knowledge, attitudes and practices) and independent (demographic information) variables of the study population.

\subsection{Ethical Consideration}

Approval for the study was obtained from the University of Namibia Postgraduate Studies Committee (PGSC) and permission was obtained from the Ministry of Health and Social Services Research Ethics Committee as well as the Research Ethics Committee of the University of Namibia. The researcher also obtained permission from the //Karas Regional Directorate of the Ministry of Health and Social Services and Keetmanshoop District Management Committee before commencing with data collection.

Informed written consent was obtained from the study participants. Participants were voluntary participate. The participants were not exposed to any physical, psychological and emotional harm and were reassured and treated in a friendly way during the interviews which were conducted in a quiet environment in a private room in the health facilities (Polit \& Beck, 2010). The participants were informed that they might not directly benefit from the research, as there were no incentives given, but their valuable information will be helpful for the future patients' intervention with regards to treatment adherence.

\section{Results}

A total number of 76 patients on tuberculosis treatment were enrolled in the study and provided data covering their socio-demographic data, knowledge, attitudes and practices pertaining to their tuberculosis treatment disease at Keetmanshoop district health facilities. The presentation is therefore structured along this line and the further analysis that examined relationship between the key variables.

\subsection{Section A: Socio-demographic Data}

The demographic data of the respondents was collected to determine their background in relation to knowledge, attitudes and practices of patients who were on tuberculosis treatment at Keetmanshoop district. This information included the age, sex, whether they had attended school and education level, marital status, residential area, employment status and occupation.

\subsubsection{Age of Respondents}

In the results, approximately $34 \%$ of the respondents were under the age category 29 to 39 years $(34.21 \%, n=26)$ while the least represented were those aged $51-60$ years $(7.89 \%, n=6)$.

\subsubsection{Gender of Respondents}

More than half, of the respondents in this study were male $(57.89 \%, n=44)$ and female were $42.11 \%(n=32)$.

\subsubsection{School Attendance and Level of Education}

The respondents were asked whether they had attended school or not of which $92.11 \%(\mathrm{n}=70)$ of the respondents indicated "yes" and 7.89\% (n=6) indicated "no". With regard to educational level of the respondents $60.53 \%(\mathrm{n}=$ 46) of respondents attained secondary level, $28.95 \%(n=21)$ had a primary education level, and only $2.63 \%(n=2)$ had attained tertiary level.

\subsubsection{Marital Status}

The majority of the respondents $(64.47 \%, \mathrm{n}=49)$ were single. Only $15.79 \%(n=12)$ of the respondents were married, while $10.53 \%(\mathrm{n}=8)$ were divorced, and $5.26 \%$ $(n=4)$ were widow/widower, while $3.95 \%(n=3)$ were co-habiting without being legal married.

\subsubsection{Respondents' Place of Residence}

In this study an equal number of the respondents were living in urban and rural area $(43.42 \%, n=33)$ respectively 
and $13.16 \%(\mathrm{n}=10)$ of the respondent were living in (peri-urban) shantytowns.

3.1.6. Employments Status

Only $31.58 \%(\mathrm{n}=24)$ of the respondents were employed and $68.42 \%(\mathrm{n}=52)$ of the respondents were unemployed.

\subsubsection{Occupation}

The majority of the respondents were unemployed $68.42 \%$ $(n=52)$ and among those who were employed majority were in informal sector $19.74 \%(\mathrm{n}=15)$.

\subsubsection{Duration on Treatment}

Respondents were asked to indicate how long they have been on tuberculosis treatment. A $13.16 \%(n=10)$ were on the tuberculosis treatment for one month, $21.05 \%(\mathrm{n}=16)$ were on the treatment for two months and $65.79 \%(n=50)$ were on treatment for three months or more.

\subsection{Knowledge of Respondents about TB Disease and Its Treatment (Section B)}

This section presents the findings on the knowledge of the patients concerning tuberculosis and TB treatment with regards to signs and symptoms, knowledge of risk factors for tuberculosis transmission, the outcome of voluntarily interrupting treatment and knowledge whether tuberculosis is curable.

\subsubsection{Respondents Knowledge of Tuberculosis Signs and Symptoms}

Figure 1 below summarizes the knowledge (agree by the respondents) on the signs and symptoms of TB.

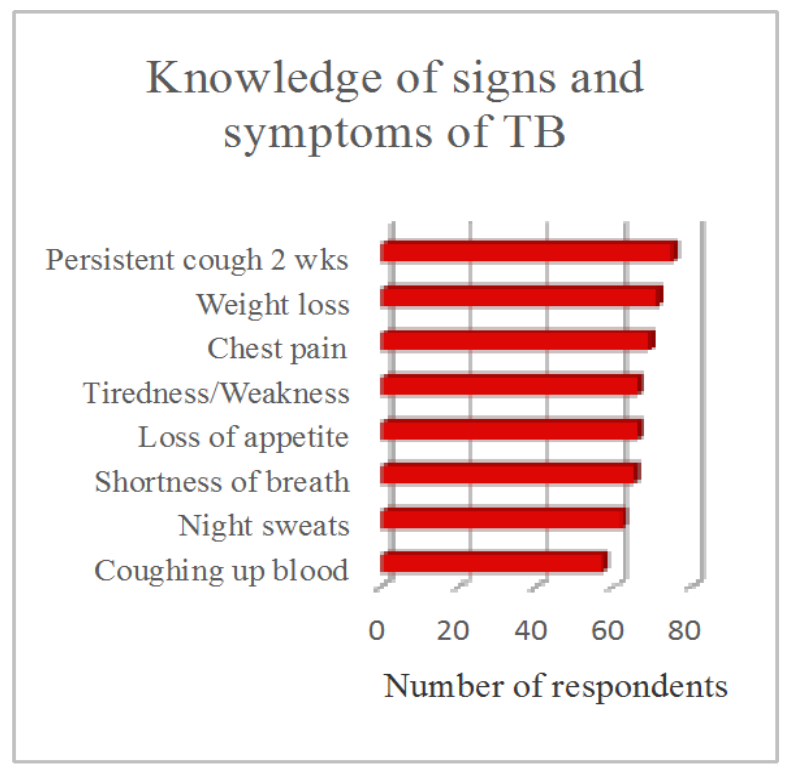

Figure 1. Respondent knowledge of signs and symptoms of tuberculosis (TB) disease $(\mathrm{N}=76)$

From the data presented in fig 1 above, the three most commonly known signs and symptoms of TB indicated by the respondents included persistent cough for 2 weeks or more, weight loss and chest pain. The least cited symptoms and signs of TB, indicated by respondents included night sweats and coughing up blood. 


\subsubsection{Respondents Knowledge of Risk Factors for Tuberculosis Transmission}

Table 1. Respondents' knowledge of risk factors for transmission of tuberculosis $(\mathrm{N}=76)$

\begin{tabular}{|l|c|c|c|c|}
\hline \multicolumn{1}{|c|}{ Risk factor } & Agree (\%) & Disagree (\%) & Don't Know (\%) & Total (\%) \\
\hline $\begin{array}{l}\text { Drinking from the same cup } \\
\text { with others }\end{array}$ & $42(55.26)$ & $29(38.16)$ & $5(6.58)$ & $76(100)$ \\
\hline Shaking hands & $30(39.47)$ & $41(53.95)$ & $5(6.58)$ & $76(100)$ \\
\hline $\begin{array}{l}\text { Coughing without covering } \\
\text { mouth }\end{array}$ & $74(97.37)$ & $2(2.63)$ & 0 & $76(100)$ \\
\hline Gathering at social events & $49(64.47)$ & $25(32.89)$ & $2(2.63)$ & $76(100)$ \\
\hline $\begin{array}{l}\text { Sharing a room with more than } \\
5 \text { people }\end{array}$ & $58(76.32)$ & $16(21.05)$ & $2(2.63)$ & $76(100)$ \\
\hline Smoking tobacco & $53(69.74)$ & $20(26.32)$ & $3(3.95)$ & $76(100)$ \\
\hline Drinking alcohol & $45(59.21)$ & $29(38.16)$ & $2(2.63)$ & $76(100$ \\
\hline $\begin{array}{l}\text { Working on road construction } \\
\text { exposed to dust or cement }\end{array}$ & $58(76.32)$ & $17(22.37)$ & $1(1.32)$ & $76(100)$ \\
\hline
\end{tabular}

Table 1 above indicates the respondents' knowledge of tuberculosis transmission risk factors. The risk factors were formulated to include both positively associated factors with $\mathrm{TB}$ and those not associated with $\mathrm{TB}$ in order to properly assess the respondents' knowledge of $\mathrm{TB}$ transmission.

\subsubsection{Knowledge of Outcome If TB Treatment Is Interrupted}

The respondents had to indicate whether they agreed, disagreed or did not know about the possible outcome for treatment interruption: treatment failure, drug resistance and death.

Table 2. Knowledge of Outcome if TB treatment is interrupted ( $\mathrm{N}=76$ )

\begin{tabular}{|c|c|c|c|c|}
\hline Outcome & $\begin{array}{c}\text { Agree } \\
(\mathbf{\%})\end{array}$ & $\begin{array}{c}\text { Disagree } \\
(\mathbf{\%})\end{array}$ & $\begin{array}{c}\text { Don't } \\
\text { Know (\%) }\end{array}$ & $\begin{array}{c}\text { Total } \\
\mathbf{( \% )}\end{array}$ \\
\hline $\begin{array}{c}\text { Treatment } \\
\text { failure }\end{array}$ & $\begin{array}{c}72 \\
(94.74)\end{array}$ & $2(2.63)$ & $2(2.63)$ & $\begin{array}{c}76 \\
(100)\end{array}$ \\
\hline $\begin{array}{c}\text { Drug } \\
\text { resistance }\end{array}$ & $\begin{array}{c}68 \\
(89.47)\end{array}$ & $6(7.89)$ & $2(2.63)$ & $\begin{array}{c}76 \\
(100)\end{array}$ \\
\hline Death & $\begin{array}{c}71 \\
(93.42)\end{array}$ & $2(2.63)$ & $3(3.95)$ & $\begin{array}{c}76 \\
(100)\end{array}$ \\
\hline
\end{tabular}

\subsubsection{Is Tuberculosis Disease Curable?}

Respondents were asked to indicate whether tuberculosis is curable or not.

A $96.05 \%(n=73)$, indicated "yes" to the question whether tuberculosis is curable and only $3.95 \%(n=3)$ of the respondents did not know whether tuberculosis is curable.

\subsection{Attitudes and Practice of Patients Who Were on Tuberculosis Treatment in Keetmanshoop District (Section C)}

In this section the results of the respondents with regards to attitudes and practices when diagnosed with tuberculosis as well as practices that may impact on their treatment is presented.

\subsubsection{Attitudes of Patients Who Were on Tuberculosis Treatment in Keetmanshoop District}

The respondents' reactions when they were diagnosed with tuberculosis were assessed using the following questions.

\subsubsection{Did You Tell Your Family Members about Your TB Treatment?}

Most of the respondents $(97.37 \%, \mathrm{n}=74)$ stated that they informed their family members about being diagnosed with tuberculosis and only $2.63 \%(\mathrm{n}=2)$ of the respondents did not tell their family members about their tuberculosis diagnosis.

\subsubsection{What Were Your Family Reactions When You Informed Them That You Were on Tuberculosis Treatment?}

Respondents were asked about their family reaction when they informed them that they were taking tuberculosis treatment. The possible family reactions were provided as option and respondents were asked to indicate whether they agreed, disagreed and did not know. Table 3 below presents the responses: 
Table 3. Family members' reaction to news of patient's TB disease $(\mathrm{N}=76)$

\begin{tabular}{|l|c|c|c|}
\hline \multicolumn{1}{|c|}{ Possible family reaction } & Agree \% (n) & Disagree \% (n) & Do not know \% (n) \\
\hline They wanted you to stay away from them & $16 \%(12)$ & $84 \%(64)$ & $0 \%(0)$ \\
\hline They encouraged you to follow what your doctors told you. & $97 \%(74)$ & $3 \%(2)$ & $0 \%(0)$ \\
\hline They were willing to remind you to take the medication everyday & $88 \%(67)$ & $12 \%(9)$ & $0 \%(0)$ \\
\hline They felt that it is not your fault to get TB & $86 \%(65)$ & $14 \%(11)$ & $0 \%(0)$ \\
\hline They feared to be infected with TB bacteria & $66 \%(50)$ & $33 \%(25)$ & $1 \%(1)$ \\
\hline
\end{tabular}

\subsection{Practice of Patients Who Were on Tuberculosis Treatment in Keetmanshoop District (Section C)}

The following questions were used to assess the practice of patients on tuberculosis treatment in Keetmanshoop district.

\subsubsection{Smoking and Drinking Alcohol}

\section{- Do you smoke?}

This question was asked to determine whether the respondents do smoke and the responses showed that $39.47 \%(\mathrm{n}=30)$ of the respondents were smokers and $60.53 \%(n=46)$ were not smokers.

\section{- Do you drink alcohol?}

The question was asked to determine whether the respondents were taking alcohol or not. Of the respondents $42.11 \%(n=32)$ indicated that they do consume alcohol and $57.89 \%,(n=44)$ indicated that they were not drinking alcohol.

\subsubsection{How Do You Take Your TB Medicines?}

Thirty-one $(40.79 \%)$ of the respondents indicated that they travelled to the clinic to drink their pills on a daily basis, followed by $35.53 \%(n=27)$ who indicated that they take their tuberculosis medicines at home supervised by a relative or treatment supporter, while $3.95 \%(n=3)$ of the respondents took their tuberculosis medicine at home supervised by health extension worker. Twelve respondents $(15.79 \%)$ were hospitalized and the nurses gave medications and $3.95 \%(n=3)$ of the respondents took their medicines at home alone without supervision.

\subsubsection{Have You Experienced Any Side Effects of the Medicines?}

The respondents were asked to indicate whether they had experienced medicine side effects or not. Twenty-two respondents $(28.95 \%)$ stated that they had experienced medicine side effects, but majority $(71.05 \%, \mathrm{n}=54)$ stated that they did not experience such side effects.

\subsubsection{How Did You Manage the Side Effects?}

Respondents who experienced medicine side effects were asked to indicate how they managed the side effects. Out of these 22 respondents, $22.73 \%(n=5)$ indicated that the medicine side effects disappeared without intervention applied, while for most of them $(77.27 \%, \mathrm{n}=17)$ they reported to health workers and none of them stopped taking their pills after they experienced side effects.

\subsubsection{Have You Ever Missed Your TB Treatment?}

This question was asked to determine whether respondents missed their treatment or not. One third of the respondents $(33 \%, \mathrm{n}=25)$ had missed their treatment, whilst $67 \%(n=51)$ of the respondents said they took their medications without missing a dose.

\subsubsection{Number of Times TB Treatment Missed}

Among the 25 respondents who missed their treatment $24 \%(n=6)$ missed treatment for one time, eleven missed for three days $(44 \%)$, and $24 \%(n=6)$ missed treatment for more than a week and only $8 \%(n=2)$ missed treatment for two months or more. Patients on tuberculosis treatment who missed their treatment for a consecutive period of four weeks or a month is regarded as tuberculosis treatment defaulters.

\subsubsection{The Following Reasons for Missing Doses Were Indicated}

This question was answered only by the patients on tuberculosis treatment who had missed treatment $(n=25)$. Patients could indicate more than one reason for interrupting TB treatment. The following reasons for missing doses were indicated. Reasons for missing TB treatment $(\mathrm{N}=\mathbf{2 5})$

\section{- $\quad$ Feeling better}

Nine of the respondents (36\%) agreed that feeling better was a reason for missing taking pills and $64 \%(n=16)$ of the respondents disagreed.

\section{- $\quad$ Forgot to take pills}

Seventeen of the respondents (68\%) agreed that a reason for missed treatment was forgetting to take pills and $32 \%$ $(n=8)$ did not agree with the statement.

\section{- $\quad$ Long distance to health facility}

Thirteen $(52 \%)$ of the respondents agreed that a reason for missed treatment was long distance to health facility and $48 \%(n=12)$ of the respondents disagreed.

\section{- Body weakness}

Nine respondents $(36 \%)$ indicated that a reason for missed treatment was body weakness, whilst $64 \%(n=16)$ of the respondents disagreed.

\section{- $\quad$ No support from family or friends}

Seven respondents $(28 \%)$ of the agreed that a reason for missed treatment was no support from family or friends, 
whilst $72 \%(n=18)$ of the respondents disagreed.

- $\quad$ Not enough food, pills make me feel hungry

Twelve of the respondents (48\%) agreed that a reason for missed treatment was not enough food, whilst 52\% $(n=13)$ of the respondents disagreed.

- It is not important to take medicine everyday

Four of the respondents (16\%) agreed that a reason for missed treatment was feeling that it was not important to take medicine every day and $84 \% \quad(n=21)$ of the respondents disagreed.

- Health worker did not explain the consequences of not taking treatment as prescribed

Three respondents (12\%) agreed that a reason for missed treatment was due to the health worker who did not explain the consequences of not taking treatment as prescribed, whilst $88 \%(\mathrm{n}=22)$ of the respondents disagreed.

\subsubsection{What Can Be Done for Patients Not to Interrupt Treatment?}

The above question was asked to determine the respondents' practice to prevent treatment interruption. This question was answered by indicating agreed, disagreed and did not know.

\subsubsection{Intervention Needed}

- Continue with treatment despite not having any symptoms.

Sixty-two of the respondents $(81.58 \%)$ agreed that they would continue with treatment despite not having any symptoms, while $18.42 \% \quad(n=14)$ of the respondents disagreed to continue with treatment despite not having any symptoms.

- Ask relatives to remind patient on follow up date

Sixty-eight of the respondents (89.47\%) agreed that they would ask their relatives to remind them of the follow-up date, while $10.53 \%(n=8)$ disagreed to involve their relative to remind them of their follow up date.

- $\quad$ Pack health passport and medication when travelling

Seventy-three of the respondents $(96.05 \%)$ agreed that they would pack their health passport and medication when travelling away from home to prevent treatment interruption and $3.95 \%(n=3)$ of the respondents disagreed with the statement above.

- Report medication side effects to doctors or nurses.

A high proportion of the respondents $(96.05 \%, \mathrm{n}=73)$ agreed to report medication side effects to doctors or nurses and only $3.95 \%(n=3)$ of the respondents disagreed with the statement above.

\subsection{Exploring relationships and Significance Testing (Correlations)}

3.5.1. The Relationship between Demographic Variables and Knowledge of Signs and Symptoms of TB

The main sign and symptom of TB disease was taken as persistent cough for two weeks or more and this was used as the proxy for knowledge of signs and symptoms of TB by the respondents and the relationship of this knowledge explored against the demographic variables.

Table 4. The relationship between the age and education of the respondents and knowledge of signs and symptoms of TB $(\mathrm{N}=76)$

\begin{tabular}{|c|c|c|c|c|c|}
\hline Respondents & Agreed & Disagreed & Total & Chi-squared & $\mathrm{p}$-value \\
\hline Age group & & & & & \\
\hline $18-28$ & 22 & 1 & 22 & \multirow{5}{*}{2.49} & \multirow{5}{*}{0.48} \\
\hline $29-39$ & 26 & 0 & 26 & & \\
\hline $40-50$ & 22 & 0 & 22 & & \\
\hline $51-60$ & 6 & 0 & 6 & & \\
\hline Total & 75 & 1 & 76 & & \\
\hline \multicolumn{6}{|l|}{ Educated } \\
\hline Yes & 69 & 1 & 76 & \multirow{3}{*}{2.47} & \multirow{3}{*}{0.11} \\
\hline No & 6 & 0 & 6 & & \\
\hline Total & 75 & 1 & 76 & & \\
\hline
\end{tabular}

The results, for the age groups p-value is 0.48 . At the $5 \%$ level of significance this means that there is no significant relationship between the age group of the respondents and their knowledge of signs and symptoms of TB disease.

While the results with relations to education is p-value is 0.11 which is more than 0.05 and indicates that there is no significant relationship between whether the person has had formal education or not and knowledge of the signs and symptoms of TB disease

\subsection{The Relationship between the Demographic Variables of the Respondents and Knowledge of Risk Factors for TB Transmission}

To examine this relationship knowledge of sharing a room with more than 5 people as a significant risk factor for TB transmission was used. The responses from the study participants were used to examine the association between the demographic variables and the knowledge of risk factors for TB transmission.

\subsubsection{The Association between the Age Group of the} Respondents and Knowledge of the Risk Factors for TB

To examine this relationship, the age group of the respondents was classified into two - below 40 years and 40 years and above. 
Table 5. The association between the age group and with relations to education, as well as between the place of residence of the respondents and knowledge of the risk factors for TB $(\mathrm{N}=76)$

\begin{tabular}{|c|c|c|c|c|c|}
\hline Respondents & Agreed & Disagreed/Don't know & Total & Chi-squared & p-value \\
\hline \multicolumn{6}{|l|}{ Age group } \\
\hline $18-39$ & 32 & 16 & 48 & 5.3 & 0.02 \\
\hline $40-60$ & 26 & 2 & 28 & & \\
\hline Total & 58 & 18 & 76 & & \\
\hline \multicolumn{6}{|l|}{ Educated } \\
\hline Yes & 54 & 16 & 70 & 0.006 & 0.94 \\
\hline No & 4 & 2 & 6 & & \\
\hline Total & 58 & 18 & 76 & & \\
\hline \multicolumn{6}{|l|}{ Residence } \\
\hline Rural & 26 & 7 & 33 & 0.03 & 0.86 \\
\hline Urban/Peri-urban & 32 & 11 & 43 & & \\
\hline \multirow[t]{2}{*}{ Total } & 58 & 18 & 76 & & \\
\hline & & 7 & 33 & & \\
\hline
\end{tabular}

The results, for the age groups p-value is 0.02 , which is less than 0.05 . This indicates there is a significant relationship between the age group of the respondents and knowledge of the risk factors for TB disease. Those respondents aged between 40-60 years appear to have more knowledge of the risk factors for TB disease than those aged 18-39 years.

\subsubsection{The Relationship between Education of the} Respondents and Knowledge of Risk Factors for TB

The relationship between having attended school or not by the respondents was correlated with their knowledge of risk factors for transmission of TB. The results with relations to education is p-value of 0.94 is higher than 0.05 and indicates there is no significant relationship between knowledge of risk factor of TB disease and whether the respondents attended school or not as showed in the finding in table 5 .

3.6.3. The Relationship between the Place of Residence of the Respondents and Knowledge of Risk Factors for TB

The place of residence as reported by the respondents was correlated with their knowledge of the risk factors for the transmission tuberculosis. The finding is shown in table 5 shows that the p-value of 0.86 indicates that there is no significant relationship between place of residence of the respondents and knowledge of the risk factors for TB disease.

\subsection{Attitudes and Practice}

The research also examined association between some of the attitude and practice variables and the reported experience of the respondents that might have effects on adherence to TB treatment.
3.7.1. Relationship between Duration on Treatment and Respondents' Experience of Side Effects of the Medicines

The research explored the relationship between the duration the respondents had been on TB treatment and their report of experience of side effects of the treatment. The data is shown in table 6 below:

Table 6. Relationship between duration on treatment and experience of side effects $(\mathrm{N}=76)$

\begin{tabular}{|c|c|c|c|c|c|}
\hline \multirow{2}{*}{$\begin{array}{c}\text { Duration on } \\
\text { treatment }\end{array}$} & \multicolumn{3}{|c|}{$\begin{array}{c}\text { Experienced side } \\
\text { effects }\end{array}$} & \multirow{2}{*}{ Chi-squared } & p-value \\
\cline { 2 - 4 } & Yes & No & Total & & \\
\hline One month & 2 & 8 & 10 & \multirow{2}{*}{0.08} & 0.77 \\
\hline $\begin{array}{c}2 \text { months and } \\
\text { more }\end{array}$ & 20 & 46 & 66 & & \\
\hline Total & 22 & 54 & 76 & & \\
\hline
\end{tabular}

The p-value of 0.77 indicates that there is no significant relationship between the duration on treatment and the respondents' reported experience of side effects of the medications.

\subsubsection{The Relationship between the Duration on Treatment and Missing the Medicines}

The research explored the possible relationship between the duration the respondents had been on TB treatment and the practice of missing some doses of the treatment. Table 7 below displays the data.

Table 7. Relationship between the duration on treatment and missing the medicines $(\mathrm{N}=76)$

\begin{tabular}{|c|c|c|c|c|c|}
\hline \multirow{2}{*}{$\begin{array}{c}\text { Duration on } \\
\text { treatment }\end{array}$} & \multicolumn{3}{|c|}{$\begin{array}{c}\text { Ever missed TB } \\
\text { treatment }\end{array}$} & \multirow[t]{2}{*}{ Chi-squared } & \multirow[t]{2}{*}{ p-value } \\
\hline & Yes & No & Total & & \\
\hline One month & 1 & 9 & 10 & \multirow{3}{*}{1.67} & \multirow{3}{*}{0.196} \\
\hline $\begin{array}{l}2 \text { months and } \\
\text { more }\end{array}$ & 24 & 42 & 66 & & \\
\hline Total & 25 & 51 & 76 & & \\
\hline
\end{tabular}

The $\mathrm{p}$-value of 0.196 indicates that there is no significant 
relationship between the duration the respondents have been on TB treatment and having ever missed their TB treatment.

\subsubsection{Relationship between Demographic Variables and} the Respondents Having Ever Missed Treatment demographic variables in relationship with practice of taking treatment. The data is presented in table 8 and the explanation of the data after the table.

The associations of respondents' demographic variables and practice with regard to having ever-missed treatment were analyzed.

This section presents the results of respondents'

Table 8. Relationship between demographic variables and the respondents having ever missed treatment $(\mathrm{N}=76)$

\begin{tabular}{|c|c|c|c|c|c|}
\hline \multirow{2}{*}{ Demographic Variable } & \multicolumn{3}{|c|}{ Ever missed TB treatment } & \multirow[t]{2}{*}{ Chi-squared } & \multirow[t]{2}{*}{ p-value } \\
\hline & Yes & No & Sum & & \\
\hline \multicolumn{6}{|l|}{ Age group } \\
\hline $18-39$ years & 16 & 32 & 48 & \multirow{3}{*}{0.02} & \multirow{3}{*}{0.88} \\
\hline $40-60$ years & 9 & 19 & 28 & & \\
\hline Total & 25 & 51 & 76 & & \\
\hline \multicolumn{6}{|l|}{ Educated? } \\
\hline Yes & 22 & 48 & 70 & \multirow{3}{*}{0.23} & \multirow{3}{*}{0.63} \\
\hline No & 3 & 3 & 6 & & \\
\hline Total & 25 & 51 & 76 & & \\
\hline \multicolumn{6}{|l|}{ Sex } \\
\hline Female & 6 & 26 & 32 & \multirow{3}{*}{3.96} & \multirow{3}{*}{$0.046^{*}$} \\
\hline Male & 19 & 25 & 44 & & \\
\hline \multirow[t]{2}{*}{ Total } & 25 & 51 & 76 & & \\
\hline & Yes & No & Sum & Chi-squared & p-value \\
\hline Marital status & & & & & \\
\hline Single & 15 & 34 & 49 & \multirow{3}{*}{0.099} & \multirow{3}{*}{0.75} \\
\hline Married/Widowed/Cohabiting & 10 & 17 & 27 & & \\
\hline Total & 25 & 51 & 76 & & \\
\hline \multicolumn{6}{|l|}{ Residence } \\
\hline Rural & 9 & 24 & 33 & \multirow{3}{*}{0.44} & \multirow{3}{*}{0.5} \\
\hline Urban/Peri-urban & 16 & 27 & 43 & & \\
\hline Total & 25 & 51 & 76 & & \\
\hline \multicolumn{6}{|l|}{ Employment status } \\
\hline Employed & 7 & 17 & 24 & \multirow{3}{*}{0.04} & \multirow{3}{*}{0.83} \\
\hline Unemployed & 18 & 34 & 52 & & \\
\hline Total & 25 & 51 & 76 & & \\
\hline
\end{tabular}




\subsubsection{Age Group}

Age group was divided into two category groups of younger and older age. This was done to examine the relationship among two age group and practice with regards to having ever-missed treatment.

The study revealed that the p-value of 0.88 indicates there is no significant relationship among age group of and having ever missed TB treatment.

\subsubsection{Education}

The p-value of 0.63 indicates no significant relationship between educated or not and having ever missed TB treatment.

\subsubsection{Sex}

The p-value is 0.046 , which is less than 0.05 this indicates there is a significant relationship between the sex of the respondents and having ever missed taking TB treatment.

\subsubsection{Marital Status}

The p-value of 0.75 indicates no significant relationship between the respondents' marital status (single and married/widowed/cohabiting) and having ever missed TB treatment.

\subsubsection{Residence}

The p-value of 0.5 indicates no significant relationship between the respondents dwelled in rural and urban/peri-urban and having ever missed TB treatment.

\subsubsection{Employment Status}

The p-value 0.83 indicates no significant relationship between the respondents' employs' status (employed or not) and having ever missed TB treatment.

\subsubsection{The Relationship between Drinking Alcohol and Having Ever Missed TB Treatment}

The researcher also examined the relationship between the practice of drinking alcohol as reported by the respondents and their having ever-missed their TB treatment. This was necessary to test the impact of drinking alcohol on missed treatment. Table 9 below presents the finding.

Table 9. Relationship between drinking alcohol and respondents ever-missed TB treatment

\begin{tabular}{|c|c|c|c|c|c|}
\hline \multirow{2}{*}{$\begin{array}{c}\text { Drinks } \\
\text { alcohol }\end{array}$} & \multicolumn{3}{|c|}{$\begin{array}{c}\text { Ever missed TB } \\
\text { treatment }\end{array}$} & \multirow{2}{*}{ Chi-squared } & p-value \\
\cline { 2 - 4 } & Yes & No & Total & & \\
\hline Yes & 14 & 18 & 32 & \multirow{2}{*}{2.16} & 0.14 \\
\hline No & 11 & 33 & 44 & & \\
\hline Total & 25 & 51 & 76 & & \\
\hline
\end{tabular}

The p-value of 0.14 is greater than 0.05 indicates that there is no significant relationship between the drinking alcohol and respondents having ever missed their TB treatment.

\section{Discussions of the Study Findings}

\subsection{Demographic Characteristics}

In this study the majority of the participants were young and middle aged people.

The finding of predominately more males over females diagnosed with tuberculosis was also reported in the study done in Dhaka city, Bangladesh by Tasnim, Rahman and Hoque (2012) and Zaranyika (2012) at Swakopmund district, Namibia. These researchers reported male to female proportions among the respondents for their study with $(55.6 \% ; 65.0 \%)$ male and female $(44.4 \% ; 45.0 \%)$ respectively.

This study revealed that $92.11 \%$ of the respondents had attended school with more respondents $(60.53 \%)$ having secondary level education and only $7.89 \%$ never had a formal education. This study result is similar to the study done by Mweemba, Haruzivishe, Chipimo, Cristenson and Johansson (2008) in Lusaka Zambia whereby $57.7 \%$ of the respondents' attained secondary or higher-level education and $42.3 \%$ had only primary education. In the present study the researcher found no significant relationship between level of education of the respondents and their adherence to TB treatment. In contrast to the study done by Chinenye (2015) reported significant relationship between educational level and practice of taking medicine regularly as prescribed, and the study found that participants with high educational level were 4.5 times higher practices in taking their medicines than those not educated.

This study revealed that equal numbers of the respondents were living in urban and rural areas $(43.42 \%$ respectively) and only $13.16 \%$ were living in shantytown (peri-urban) and $68.42 \%$ of the respondents were unemployed while $31.58 \%$ had some form of employment. A high rate of unemployment may contribute to the development of TB as a result of poverty, poor living standard and lack of adequate nutrition. Unemployment may also lead to poor nutrition, inability to afford transport costs to the health facility therefore interfere with adherence to TB treatment. Good nutrition is needed during TB treatment for successful treatment of the patient (MoHSS, 2012a).

The duration of TB treatment might have an influence on the knowledge of the respondents regarding tuberculosis because when exposure to taking treatment is longer and it increase the experience of the respondents. In this study fifty of the respondents $(65.7 \%)$ had been on TB treatment for more than three months and this might have increased their knowledge of TB and TB medicines because they had been well exposed to health education on TB during clinical appointments. 


\subsection{Knowledge of Respondents about Signs and Symptoms}

The study revealed that the respondents had good knowledge with regards to the most common signs and symptoms of tuberculosis such as persistent cough for two weeks or more $(98.68 \%)$, chest pain $(90.79 \%)$, weight lost $(93.42 \%)$, shortness of breaths $(85.5 \%)$ tiredness or weakness $(86.84 \%)$. This is in contrast to a study done by Kenyi et al. (2012) in Juba City, South Sudan where it was reported that $52 \%$ of the respondents did not have good knowledge of signs and symptom of tuberculosis.

Good knowledge on the signs and symptoms might be influenced by the fact that some patient experienced the same signs and symptoms before being diagnosed with tuberculosis. The study found that there was no significant relationship between the age of the respondents, their educational level, gender, place of residence, marital status and duration on treatment and knowledge of the signs and symptoms of TB disease. In this study good knowledge of signs and symptoms of TB seems not to make any positive impact on respondents' adherence to tuberculosis treatment.

\subsection{Respondents Knowledge of Risk Factors for Tuberculosis Transmission}

The study has revealed that the majority of the respondents had a good knowledge of the risk factors for transmitting tuberculosis such as coughing without covering the mouth (99\%); gathering at social events $(64.47 \%)$; sharing room with more than five people (76.32\%); which all can put other persons at risk of getting tuberculosis. This study equally found that some of the respondents harbor some misconceptions or myths associated with the transmission of tuberculosis. Some of the respondents wrongly believed risk factors for transmitting tuberculosis included shaking hands with TB patient, which was indicated by approximately $40 \%$ of the respondents and about $76 \%$ of the respondents wrongly believed that working on road construction and exposure to dust or cement could cause TB.

Poor knowledge of risk factors in transmission of TB was confirmed by responses on the drinking in same cup with others $(55.26 \%)$ and working on road construction exposed to dust or cement $(76.32 \%)$ in transmitting TB. The study found significant association between knowledge of risk factor and age group of the respondents. There was no association between knowledge of the risk factors and other demographic variables. This finding of respondents' poor knowledge of the risk factors in transmitting tuberculosis is in line with a study done by Agho et al. (2013) using data from the Nigeria Demographic and Health Survey, whereby the respondents indicated that tuberculosis can be transmitted by touching a TB patient $(3.9 \%)$, sexual contact $(5.0 \%)$, using same utensil (36.5\%) and TB spread through food (11\%).
Among other demographic variables a significant relationship was found between the age group of the respondents and knowledge of risk factors for tuberculosis with a p-value of 0.02 . The aged group 40-60 appeared to have more knowledge of risk factors for tuberculosis than those aged 18-39 years. The reason for this might be that the older persons have experience and longer exposure to health information than the younger members of the population. Poor knowledge of the risk factors for transmission and misconceptions may lead to stigma and discrimination for TB patients and may lead to failure to disclose their TB infection to their family and close relatives. This may negatively impact on their adherence to their TB treatment and may result in poor treatment outcomes.

\subsection{Knowledge of the Outcome If Tuberculosis Treatment Is Interrupted}

Most of the respondents (94.74\%) had a good knowledge about the outcome when tuberculosis treatment is interrupted, which account to treatment failure. Knowledge on drug resistance (89\%) and death (93.42\%) in interrupting treatment was also good. Few of the respondents did however not know the outcome when tuberculosis treatment is interrupted. Knowledge of the outcome if treatment is interrupted did not seem to correlate with patients' decision to miss the doses of the medication. Poor knowledge of the outcome of interruption of treatment may be associated with stopping treatment, because patients do not have awareness of the dangers of interrupting TB treatment. This is in line with a study done by Dladla (2013), in Waterberg district in Limpopo province, South Africa whereby $4 \%$ of the respondents believed that TB cannot result in death if not treated. If patients have a poor knowledge of the outcome if treatment is interrupted this may result in poor treatment adherence and subsequently development of drug resistant TB, which have serious consequences for the patient and the public health system in general.

\subsection{Knowledge of the Respondents Whether Tuberculosis Is Curable}

The study found that most of the respondents (96.05\%) had good knowledge that tuberculosis is curable. This is in agreement with a study done in Sudan by Mohamed, Pharm, Yousif, Ottoa and Bayoumi (2007) whereby $80.3 \%$ of the respondents knew that tuberculosis is curable. However, the present study did not demonstrate any significant association between the knowledge that TB is curable and adherence of the respondents to their TB medications. This study found also that approximately $4 \%$ of the respondents did not know whether tuberculosis is curable. Patients who experienced TB relapse or have known a patient with TB relapse or treatment failure might be the ones who held this perception. Tuberculosis infection does not confer 
life-long immunity; hence relapse or new infection is possible.

\subsection{Attitudes regarding Tuberculosis Treatment}

The attitudes of the patient while on treatment are important variables in the treatment success. This study revealed that most of the respondents' $(93.42 \%)$ reaction to news of being diagnosed with tuberculosis indicated they accepted it without worry, but $60.53 \%$ of the respondents were afraid of transmitting the disease to the family member, whilst $26.32 \%$ of the respondents reported that they were felt embarrassed and isolated. In many societies including Namibia TB is still a dreaded disease and patients with TB are stigmatized. Hence disclosing that person has TB infection takes some efforts and persuasion from health workers.

This study found that $97.37 \%$ of the respondents indicated they disclosed their tuberculosis diagnosis to family members. This is in contrast to the study done by Kenyi (2015), whereby $91.2 \%$ of the respondents did not disclose to the family or community member that they had tuberculosis, but rather preferred to call their illness other names like chronic cough or chest disease. It is important for the patients diagnosed with $\mathrm{TB}$ to disclose their tuberculosis infection to family members and close contacts to avoid the spreading of the disease in the community and accord such family members and contacts the opportunity to go to the health facilities for TB screening. It is therefore a positive attitude and practice that respondents in this study indicated they did tell contacts/family about their TB diagnosis.

\subsection{Practice regarding Tuberculosis Treatment}

The health services and community have a collective responsibility of ensuring that patients started on TB treatment take all their medicine as prescribed (MOHSS, 2012a). The TB nurse or TB Field Health Promoter should put the TB treatment card aside when a patient did not turn up for his/her daily DOT appointment or for collection of a weekly or 2- weekly medicine supply (MOHSS, 2012a). After a week the patients or his/her DOT supporter did not attend the health facility, the nurse should make effort to trace the patient or his/her DOT supporter. When efforts to trace the patients succeeded, the reason for treatment interruption should be established and treatment is continued as before (MOHSS, 2012a).

Out of 76 respondents $39.4 \%$ indicated they were smokers and $42.11 \%$ indicated they do consume alcohol. Smoking and alcohol consumption may interfere with the effectiveness of the medication.

A study done by Kamenye, Sumpi, Van Dyk and Ashipala (2016), on the knowledge, beliefs and practice of patients diagnosed with tuberculosis found that patients on tuberculosis treatment engaged in behavior such as drinking alcohol which might make them forget taking their medication as required. The researchers concluded that individual health education should be emphasized to make people aware of unhealthy lifestyle and refrain from it in order to ensure treatment effectiveness (Kamenye et al., 2016).

The finding in this study $67 \%$ of the respondents took their medications regularly without missing a single dose, is much lower than that reported in study by Chinenye (2015) in Kigali, Rwanda where (83.9\%) of the respondents reportedly took their medicines without missed doses.

This study also found significant relationship between the sex of the respondents and having ever missed taking tuberculosis treatment, the p-value 0.046. Where a high proportion of the patients miss taking their TB medicines regularly it portends a great danger to a public health system in addition to the poor treatment outcome quality of life for individual. Treatment adherence is a big challenge in the management and control of tuberculosis (MoHSS, 2012a).

Less than one third of the respondents in this study experienced medicine side effects, which either disappeared on its own or they sought help from the nurse or doctor. The experience of side effects was not a significant reason for the patients in this study to miss their treatments.

The main reason given for the interrupting medication were forgetting to take pills (68\%); long distance to health facility (52\%); not enough food to eat before taking pills $(48 \%)$; body weakness $(36 \%)$, feeling better $(36 \%)$; no support from family/friends (28\%); thinking that it was not important to take pills everyday (16\%) and health worker did not explain the consequences of missing treatment $(12 \%)$. In a similar study done in Morroco by Tachfouti et al., (2012), the reasons given by the respondents for premature stopping to take their treatment were feeling better $(72.9 \%)$, long duration on the treatment $(34.1 \%)$ and difficulty to access health facility (4.7\%).

This study found good attitudes to treatment by the respondents as almost $82 \%$ of the respondents were of the opinion that to prevent treatment interruption patients who are on treatment should continue with treatment despite not having any symptoms, and $89 \%$ of them stated that they would ask a relative to remind them on follow up date. Ninety-six percent of the respondents also indicated that patients on treatment should pack their health passport when travelling and $95 \%$ stated that patients on treatment should report medication side effect to the doctor or nurse. In contrast, in a study done by Dladla (2013), only $20 \%$ of the respondents indicated they wanted support from their family, $18 \%$ stated that healthcare worker attitudes towards TB patients should change, $16 \%$ of the respondents wanted ongoing education on the dangers of not completing TB treatment, $15 \%$ indicated that TB clinic should be open on weekends for patients to refill their TB drugs and $11 \%$ wanted food parcels for TB patients in order to increase 
their compliance to TB treatment. A positive attitude to treatment is a good omen for the patients to adhere to treatment especially in long-term care for conditions such as tuberculosis. This ensures completion of treatment, better outcomes and general improvement in the health status of the community.

\section{Conclusions}

The study revealed that the respondents had a good knowledge on some aspect of TB such as main signs and symptoms of tuberculosis, factors associated with risk of transmissions of tuberculosis, and problems that may arise if treatment is voluntarily interrupted. However, some of the respondents had misconceptions and poor knowledge with regards to some risk factors of transmission such as the belief that shaking hands with a TB patient, drinking from the same cup and drinking alcohol could lead to transmission of TB.

Although most of the respondents knew that tuberculosis is curable among the respondents there were some who missed taking their treatments.

The study has therefore highlighted gaps between knowledge and practice among the patients who are on TB treatment in the Keetmanshoop district. Some factors such as forgetfulness, long distance to health facilities, lack of food and poor health education from the health care workers were highlighted by the respondents as factors that hindered them to take their medication regularly as prescribed thus impacting on adherence.

\section{Recommendation}

- The researcher found that one of the reasons stated by the respondents for non-adherence to their medications was the long distance to travel to the health facilities to their medicines. It is hereby recommended that the Minister of Health and Social Services, //Karas Regional Directorate to take urgent steps to train and deploy health extensional workers to every village in the district to assist in providing DOT for TB patients who are resident within the village cluster.

- $\quad$ Nurses, TB field promoters and the health extensional workers as well as Doctors should continuously provide health information regarding tuberculosis disease, the risk factors, signs and symptoms, prevention, importance of taking and adhering to tuberculosis treatment and avoiding unhealthy lifestyle such smoking and drinking alcohol needs to be intensified. Patients who have completed their TB treatment and are healthy could be employed as role model to motivate and support TB patients who are still undergoing treatment.

\section{Acknowledgements}

- The researchers give special thanks to the Post Graduate Committee of the University of Namibia and Ministry of Health and Social Services for giving us permission to carry on with the research at Keetmanshoop Health district.

- We thank the (Acting) Director of $/ /$ Karas Regional Health Directorate Dr. Job Ndile, Senior Medical Officer for Keetmashoop district Dr. Kooper, and PHC Supervisor Sr. Namukwambi, the District TB and Leprosy Coordinator Mr. Moses Katandawa and the TB Field Promoters who assisted us during data collection. We thank the patients who were on tuberculosis treatment who voluntarily participated in the research and Dr. Ebong Akpabio for assisting us with statistical analysis and editing.

- Finally, we would like to thank colleagues, friends and family for their invaluable support.

\section{REFERENCES}

[1] Agho, K. E., Hall, J., \& Ewald, B. (2014). Determinants of the Knowledge of and Attitude towards Tuberculosis in Nigeria. [online] Journal of Health, Population, and Nutrition, 32(3), 520-538. https://www.ncbi.nlm.nih.gov/p mc/articles/PMC4221458/

[2] Castelnuovo, B. (2010). A review of compliance to anti tuberculosis treatment and risk factors for defaulting treatment in Sub Saharan Africa. [online] African Health Sciences, 10(4), 320-324. https://www.ncbi.nlm.nih.gov/p mc/articles/PMC3052808/

[3] Chinenye, N. M. (2015). Evaluation of Knowledge, Attitude and Practices of TB Diagnosed Patients in Rwanda towards TB Infection. Case of TB Diagnosed Patients in Kigali Urban and Rural Health Facilities. [online] International Journal of Scientific and Research Publications, Volume 5, Issue 8, August 2015 www.ijsrp.org/research-paper- 0815/i jsrp-p4482.pdf

[4] Dladla, C.N. (2013). Factor Contributing to Non-Compliance to PulmonaryTuberculosis Treatment among Patients in Waterberg District Limpopo Province (Master's thesis). South Africa: University of South Africa. https://www.google.ru/url?sa=t\&rct=j\& $\mathrm{q}=\&$ esrc $=$ s\& source =web\&cd=1\&ved=0ahUKEwiSwMDtrfrUAhWFJsAKHU ZTCEkQFgghMAA\&url=http\%3A\%2F\%2Fuir.unisa.ac.za $\% 2$ Fbitstream\%2F10500\%2F9268\%2F1\%2Fdissertation dladla_cn.pdf\&usg=AFQjCNEjuxYBoWqW96yqmoM8C PmoZ̄ouzdw\&cad=rjt

[5] Kamenye, E., Sumpi, N., Van Dyk, A., \& Ashipala D. O. (2016). A study on knowledge, beliefs and practices of patient diagnosed with tuberculosis, Katutura, Khomasdal Windhoekhttps://www.sciencepubco.com/index.php/IJAN S/article/download/6387/2356

[6] .Kenyi, L. J., Martin, T., Ohisa, G., Matthew D., Macharia, S., \& Joseph, L. (2014). Knowledge, attitude and practice (KAP) of tuberculosis patient enrolled on treatment in Juba 
City, South Sudan 2010: a pilot study. [online] South Sudan Medical Journal, May 2014 Vol .7(2) http://www.southsud anmedicaljournal.com/archive/may-2014/knowledge-attitu de-and-practicekap-of-tuberculosis-patients-enrolled-on-tre atment-in-juba-city-south-sudan2010.-a-pilot-study.html

[7] Mangesho, P. E., Shayo, E., Makunde W. H., Keto, G. B., Mandara C. I., Kamugisha, M. L., Kilale, A. M., \& Ishengoma, D. R. (2012). Community knowledge, attitudes and practices towards tuberculosis and its treatment in Mpwapwa district, central Tanzania. https://www.ncbi.nlm .nih.gov/pubmed/17547099

[8] Maree, K. (2009). First steps in research. Pretoria, South Africa: Van Schaik Publishers.

[9] Mweeba, P., Haruzivisishe, C., Siziya, S., Chipimo, P.J., Criteson, K., \& Johansson, E. (2008). Knowledge, attitude and Compliance with Tuberculosis Treatment, Lusaka, Zambia. Medical Journal of Zambia: Vol. (35) (4). https://www.ajol.info/index.php/mjz/article/download/560 $64 / 44520$

[10] Ministry of Health and Social Services. (MOHSS). (2012a). National Guideline

[11] Ministry of Health and Social Services (MOHSS). (2012b). National Tuberculosis and Leprosy Programme: Annual Report (2012-2013). Namibia: Windhoek

[12] Ministry of Health and Social Services (MOHSS). (2016). National Tuberculosis and Leprosy Programme: Annual Report (2015-2016). Namibia: Windhoek

[13] Mohammed, A. I., Tousif, M. A., Ottoa, P., \& Bayoumi, A. (2007). Knowledge of Tuberculosis in Omdurman, Sudan. Sudanese Journal of Public Health: January 2007, Vol. (2) (1). https://www.researchgate.net/publication/270958019 Knowledge_of_Tuberculosis_A_Survey_among_Tubercul osis_Patients_in_Omdurman_Sudan

[14] Polit, D. F., \& Beck, T. C., (2010). Essentials of Nursing Research: Appraising Evidence for Nursing Practice. China: Wolters Kluwer Health/ Lippincott Williams \& Wilkins

[15] Tachfouti, N., Slama, K., Berraho, M., \& Nejjari, C. (2012). The impact of knowledge and attitudes on adherence to tuberculosis treatment: a case- for the Management of Tuberculosis. 3rd edition. Namibia: Windhoekcontrol study in a Moroccan region. Pan Afr Med J, (12): 52. [PMC free article] [PubMed]

[16] Tasnim, S., Rahman, A., \& Hoque, F.M.A (2012). Patient's Knowledge and Attitude towards Tuberculosis in an Urban Setting. [online] http://dx.doi.org/10.1155/2012/352850

[17] World Health Organization (WHO). (2011). Global Tuberculosis Report 2011. Available from http://apps.who. int/iris/bitstream/10665/44728/1/9789241564380_eng.pdf

[18] World Health Organization (WHO). (2012). Global Tuberculosis Report 2012; [online]WHO/HTM/TB/2012.6, Geneva. Retrieved on 31.05.2013 from WHO web site http://www.who.int/about/licensing/copyright_form/en/ind ex.html

[19] Zaranyika, T. (2012). Treatment interruption in Tuberculosis Patients in a District of Namibia (Master's thesis). University of South Africa. Retrieved from https://core.ac. uk/download/pdf/43169750.d 